\title{
Updating the definition of pain
}

Amanda C de C Williams ${ }^{1}$, PhD, Kenneth D. Craig ${ }^{2}, \mathrm{PhD}$

${ }^{1}$ Research Department of Clinical, Educational \& Health Psychology, University College

London, London UK

${ }^{2}$ Department of Psychology, University of British Columbia, Vancouver, British Columbia,

Canada

Corresponding author: Amanda C de C Williams

Research Department of Clinical, Educational \& Health Psychology,

University College London, Gower St., London WC1E 6BT, UK

Tel: 00442076791608

Fax: 00442079161989

Email: amanda.williams@ucl.ac.uk

Keywords Experience; Sensation; Emotion; Cognition; Social; Assessment

Word count: 1996 


\section{Introduction}

The definition of pain promulgated by the International Association for the Study of Pain (Box 1) has provided a powerful conceptual anchor for scientific and healthcare professional advances in understanding the nature and treatment of acute and chronic pain. Based on work by Merskey in 1964 [22], it has been widely endorsed and even more widely used [27], with the primary text unchanged since first published in 1979 [15]. Since then there have been substantial advances in our understanding of pain, in assessment and treatment, employing a multidisciplinary perspective, and emergence of chronic disease models. These advances instantiate the biopsychosocial perspective on pain that was required to capture evidence-based understanding and the evolution of pain care. While the IASP definition was under development, Melzack and Wall (1965) published "Pain Mechanisms: A New Theory" in Science [21], generating a revolution in our understanding of pain mechanisms and management [16].

In light of these advances, a review of the definition of pain seems warranted. We provide a rationale explaining why a revised definition better captures the essence of what we presently understand to be pain and how it would better equip those who try to control pain. The following definition is proposed:

Pain is a distressing experience associated with actual or potential tissue damage with sensory, emotional, cognitive and social components.

\section{Box 1 about here}




\section{The current definition}

A definition needs to 'describe a thing according to its properties' [5], identifying what it is and is not, providing direction for scientific understanding and, in this case, for clinical interventions. Does the current definition describe essential and fundamental properties? Does it differentiate pain from other 'things' or events? Without criteria for adequacy, the user must decide.

The current definition has enjoyed widespread use, but not without criticism and some revisions to the Note. Careful inspection reveals strengths and difficulties. It effectively describes the essential subjectivity of pain experience, differentiating it from physiological processes, although at another level of understanding, biological mechanisms govern that experience. It facilitates appreciation of the multidimensional nature of pain by specifying both sensory and emotional features; including emotion was a major advance over an exclusively sensory focus on pain $[21,23]$. The definition is brief and succinct, supporting easy use. It has provided a common understanding of a serious health problem across a remarkable diversity of scholarly, scientific and health care professions.

An essential feature is the assertion that pain is associated with actual or potential tissue damage, denoting this as a necessary characteristic of the experience, but also recognizing that events other than tissue damage can serve as determinants, consistent with a biopsychosocial model of pain $[12,13]$, and encouraging specification of multiple causal factors beyond tissue pathology. 
Perhaps the most elusive part of the definition is its final phrase, "or described in terms of such damage". This was intended to acknowledge complaints of people experiencing pain without evidence of tissue stress or damage, despite thorough investigation [22], and, as a political manoeuver, the phrase provided necessary validation for many people with chronic pain. Mounting evidence of neuroplastic changes in peripheral and central nervous systems and the brain during transition from acute to chronic pain supports the wisdom of this decision, acknowledging the reality of pain in the absence of a pathophysiological basis, but perhaps these purposes place it outside the definition.

There should be good reasons to modify a widely used definition. We suggest three. First, acknowledging only sensory and emotional features excludes major and clinically important characteristics, in particular, cognitive and social components. These components are often considered to be characteristic of chronic pain and can be overlooked in understanding acute pain, despite much evidence to the contrary $[19,21,26]$. Second, characterizing the experience simply as "unpleasant" falls short: most acute or chronic clinically problematic pain is more than "unpleasant" and the term potentially trivializes severe pain. Finally, subjectivity and self-report are prioritized at the expense of nonverbal behaviors, prominent sources of information about pain in human and nonhuman animals, particularly those whose subjective experience cannot be communicated.

\section{Defining features of pain experience}

In the $21^{\text {st }}$ Century, behavioral science and neuroscience have moved beyond introspection and description to acknowledge perceptual, affective and cognitive features of experience. To focus 
on sensation and affect in the study of pain in nonhuman animals ignores a mounting understanding of animal cognition [19] and social behavior [26], but the main cost is explicit disregard for human cognitive abilities to influence both internal somatic environments (e.g., through descending inhibitory controls and self-regulation) and the external physical and social environment. Failure to acknowledge this feature of pain is a serious problem.

\subsection{Cognition}

The healthy dispute over the primacy of cognition or emotion in explaining human behavior [30,46] highlights the importance of both, long recognized in pain [36]. Interest in the nature of painful experience has drawn extensively on cognitive science methodologies [28], including from attention [10], memory [11] and language use [35]. Further, the human capacity for cognitive elaboration of pain is prominent when considering suffering, pain expression, and social parameters of pain [7,37]. Brain imaging increasingly enriches our study of subjective experience, demonstrating dynamic serial and parallel activity widely distributed in the brain [4], including important frontal lobe executive processes (e.g. 44).

Interest in structure and content of cognitive processes addresses experience: what is the individual thinking about when in pain? Self-report demonstrates a broad range of content beyond intensity [37], incorporating "nociception, emotion, decision-making, self-awareness, social cognition, and communicative tendencies" [45]. Subjective experience of pain can include perception of internal somatic events as well as experience of prior, current and anticipated environments. Because self-report is largely under personal control, it provides a medium for influencing the environment in the individual's perceived best interests. Facial and other 
behavioral expression of pain are also multidimensional—for example, facial expression can disclose various emotional and motivational states, as well as cognitive features, such as intentions, efforts at problem solving and social reactions [41].

Content of experience is a major focus of interventions using cognitive and behavioral methods [43]. Several important models, particularly those based on fear and avoidance [8] and focussing on catastrophic thinking [38], have identified important pain-associated beliefs and cognitive biases, with emotional and behavioral consequences, including decrements in cognitive processing.

\subsection{Sociality}

The definition also fails to acknowledge social dimensions, major features of human pain $[6,13]$ and identified in nonhuman animals, including the rodents extensively used in developing analgesics $[18,19,26,40]$. Humans are the quintessential social animal: big sophisticated brains evolved in progenitor hominids and homo sapiens to process complex demands of competition and cooperation [17]. Social environments determine exposure to pain, thoughts and feelings when in pain, communication of distress to others, and others' experience and responses $[6,13]$. We remind readers that health care delivery systems and all human and some animal pain studies are inherently social. A biopsychosocial model of pain requires explicit acknowledgement of sociality 


\subsection{In summary}

The existing definition is partial rather than complete, omitting essential qualities necessary to promote good science and optimal health care. Its originators achieved a great deal, but reflected their times; the intervening 50 years of research and clinical advances in pain need to be incorporated, directing attention to key concerns. Including cognitive and social dimensions provides a balanced and more comprehensive perspective. Further, we need to move beyond the primacy of pain complaint [1], an important but distracting political and rhetorical feature of the original definition, and recognize that pain has functional, adaptive value through a broader range of nonverbal behaviors.

\section{Facilitating assessment in research and clinical settings}

The definition is, appropriately, the foundation of assessment methods and practices. Unfortunate features of the original definition were (1) the implication that self-report was the standard, and (2) failure to address dimensions of pain assessment directly. Although self-report in humans allows rich communication about pain, in practice, pain scientists and clinicians often focus on unidimensional, sensory intensity [37]. In contrast, effective clinicians integrate extensive patient self-report with their assessment of nonverbal behaviors, aspects of voice, body activity and facial activity, to enhance understanding. We need to acknowledge that any clinical assessment is, effectively, a social event [33], with self-report more than a 'readout' of an internal state; but a verbal behavior subject to contextual influence. Further, the definition's focus on self-report has rightly been criticized [1] for excluding humans who cannot describe their experience, because of underdeveloped or impaired cognitive capacities, or because they have no adequate language. Fortunately, the Note was revised in 2002 to acknowledge the 
importance of attending to pain in people unable to make self-report [14]. The central requirement of self-report also precludes assessment of pain in animals, at odds with much pain and analgesic research $[9,39]$ and the evolutionary continuum [42].

Removing references to assessment processes from the definition to the Note section is preferable. We recommend incorporating reference to a broad range of behaviors $[20,31]$ in all assessment, encouraging broader assessment than self-report. Respect for ethnic and cultural diversity also requires attention to behavior in pain. Nonverbal behaviors associated with pain are no more closely correlated with evidence of tissue damage than self-report and often have only a weak relationship with reported pain; better to consider self-report as only one of many behaviors communicating painful distress. Very few behaviors are specific to pain, and we have little understanding of the diverse functions of behaviors associated with pain [29,41], which may be classified using the dimensions reflexive/automatic vs purposive/controlled [7], or protective and/or communicative [38]. Across studies of vertebrates and invertebrate animals, some types of adaptive behavior are consistently reported in acute injury and during recovery [39]. For human and non-human animals, technology increasingly offers automated detection and assessment of various behaviors associated with pain [2.3.34,25], an otherwise labourintensive data collection task subject to bias and observation errors.

\section{Usefulness of the Note}

The Note also requires revision. We attend here only to problematic elements, not reiterating positive components. Some features of the Note are redundant, neither qualifying it nor adding information: reiterating that pain is subjective; restating the defining feature of tissue damage; 
repeating that it is both a sensation and an emotional experience. Other features elaborate on the definition without directing the reader to a clear model or practice. 1) The argument that reports of pain in the absence of tissue damage or any likely pathophysiological cause are probably psychological is outdated; neuroplasticity provides an explanation and supports the recommendations in the Note to attend to subjective experience. 2) Psychological phenomena, such as substantial emotional reactions to clinically straightforward pain, problematic thinking styles, widespread avoidance with adverse effects, and disrupted social relationships, also occur in patients with diagnosable tissue pathology. 3) Ruling out certain experiences as not painful, e.g., pricking sensations or dysesthesias, is overly conservative and confusing where these are reported as part of the pain experience. 4) The observation that pain must be assessed in those unable to communicate verbally is not explicit about nonverbal communication; above we argue that nonverbal communication plays a role in all clinical assessment and in research assessment of pain.

The proposed definition accords with Merskey's injunction, "All that is needed is to define pain in terms of what we experience as pain and leave it at that" (p. 25) [23]. Our modification reasserts the importance of subjective experience, attaches importance to thoughts and social considerations as well as sensations and emotions, acknowledges variability of the essential aversive quality in use of the word "distressing", and removes reference to assessing pain, acknowledging it in the Note. In a revised Note, we recommend emphasizing behavior in all assessment; deleting the implication that psychological problems occur only where there is no tissue damage, and avoiding dualistic distinctions. 
In closing, we aim to generate debate and discussion that will lead to an improved definition, serving all researchers and clinicians better in their work in pain, and engaging those outside the pain field whose knowledge and disciplines may enrich our understanding.

Conflict of interest: neither author has any conflict of interest to disclose. Neither author received funding for this work. 


\section{References}

[1] Anand KJS, Craig KD. Editorial: New perspectives on the definition of pain. Pain 1996;67:3-6.

[2] Aung MSH, Bianchi-Berthouze N, Watson P, Williams ACdeC. Automatic recognition of fear-avoidance behaviour in chronic pain physical rehabilitation. OldenBurg, Germany: 8th Int. Conf. on Pervasive Computing Technologies for Healthcare, 2014.

[3] Aung MSH, Kaltwang S, Romera-Paredes B, Martinez B, Singh A, Cella M, Valstar M, Meng H, Kemp A, Shafizadeh M, Elkins AC, Kanakam N, de Rothschild A, Tyler N, Watson PJ, Williams ACdeC, Pantic M, Bianchi-Berthouze N. The automatic detection of chronic pain-related expression: requirements, challenges and a multimodal dataset. IEEE Trans Affective Computing, in press.

[4] Bushnell MC, Ceko M, Low LA. Cognitive and emotional control of pain and its disruption in chronic pain. Nature Rev Neurosci 2013;14:502-511.

[5] Chambers 21st Century Dictionary. www.chambers.co.uk accessed 24.12.2015

[6] Craig KD. The social communication model of pain. Pain 2015;156:1198-1199.

[7] Craig KD, Versloot J, Goubert L, Vervoort T, Crombez G. Perceiving others in pain: automatic and controlled mechanisms. J Pain 2011;11:101-108.

[8] Crombez G, Eccleston C, Van Damme S, Vlaeyen JWS, Karoly P. The fear avoidance model of chronic pain: the next generation. Clin J Pain 2012;28:475-483.

[9] Dawkins MS. Through animal eyes: what behaviour tells us. Appl Animal Behav Science 2006;100:4-10.

[10] Eccleston C, Crombez G. Pain demands attention: A cognitive-affective model of the interruptive function of pain. Psychol Bull 1999;125:356-366.

[11] Eich E, Reeves JL, Jaeger B, Graff-Radford SB. Memory for pain: relation between past and present intensity. Pain 1985;23(4):375-380.

[12] Gatchel RJ, Peng YB, Peters ML. Fuchs PN, Turk DC. The biopsychosocial approach to chronic pain: scientific advances and future directions. Psychol Bull 2007;133(4):581-624.

[13] Hadjistavropoulos T, Craig KD, Duck S, Cano AM, Goubert L, Jackson P, Mogil J, Rainville P, Sullivan M, Williams ACdeC, Vervoort T, Dever Fitzgerald T. A biopsychosocial 
formulation of pain communication. Psychol Bull 2011;137(6):910-939. doi:

\section{$\underline{10.1037 / \mathrm{a} 0023876}$}

[14] Hadjistavropoulos T, Breau L, Craig KD. Pain assessment in adults and children with limited ability to communicate. In DC Turk \& R Melzack (Eds.), Handbook of pain assessment, $3^{\text {rd }}$ ed, New York: Guilford, 2011, pp. 260-282.

[15] IASP Subcommittee on Taxonomy. The need of a taxonomy. Pain 1979;6:249-252.

[16] Katz J, Rosenbloom BN. The golden anniversary of Melzack and Wall's gate control theory of pain: celebrating 50 years of pain research and management. Pain Res Management 2015;20:285-286.

[17] Kudo H, Dunbar RIM. Neocortex size and social network size in primates. Animal Behav 2001;61:711-722.

[18] Langford DJ, Tuttle AH, Brown K, Deschenes S, Fischer DB, Mutso A, Root KC, Sotocinal SG, Stem MA, Mogil JS, Sternberg WF. Social approach to pain in laboratory mice. Soc Neurosci 2010;5(2):163-170.

[19] Low LA. The impact of pain upon cognition: what have rodent studies told us? Pain 2013;154:2603-2605.

[20] McCrystal KN, Craig KD, Versloot J, Fashler SR, Jones DM. Perceiving pain in others: validation of a dual processing model. Pain 2011;152:1083-1089.

[21] Melzack R, Wall PD. Pain mechanisms: a new theory. Science 1965;150:971-979.

[22] Merskey H. An Investigation of Pain in Psychological Illness. Oxford: DM Thesis, 1964.

[23] Merskey H. History and definition of pain. In Rashiq S, Schopflocher D, Taenzer P, Jonsson E. Chronic pain: A health policy perspective. Weinheim: Wiley-VCH Verlag GmbH \& Co. KGaA, 2008.

[24] Merskey H, Bogduk N. Classification of Chronic Pain: Descriptions of Chronic Pain Syndromes and Definitions of Pain Terms, $2^{\text {nd }}$ ed. Seattle, WA: International Association for the Study of Pain, 1994.

[25] Miller AL, Flecknell PA, Leach MC, Roughan JV. A comparison of a manual and an automated behavioural analysis method for assessing post-operative pain in mice. Appl Animal Behav Sci 2011;131:138-144.

[26] Mogil JS. Social modulation of and by pain in humans and rodents. Pain 2015;156(4)Suppl 1:S35-S41. 
[27] Morris DB. The challenges of pain and suffering. In TS Jensen, PR Wilson, ACS Rice (Eds.), Chronic Pain. London: Arnold, 2003, pp.3-14.

[28] Neisser U. Cognitive psychology. Englewood Cliffs: Prentice-Hall, 1967.

[29] Prkachin KM. Pain behavior is not unitary. Behav Brain Sci 1986;9(4):754-755.

[30] Rachman S. The primacy of affect: Some theoretical implications. Behav Res Ther 1981;19(4):279-290.

[31] Revicki DA, Chen WH, Harnam N, Cook KF, Amtmann D, Callahan LF, Jensen MP, Keefe FJ. Development and psychometric analysis of the PROMIS pain behavior item bank. Pain 2009;146:158-69.

[32] Rey R. History of Pain. Paris: Editions de la Couverte, 1993.

[33] Schiavenato M, Craig KD. Pain assessment as a social transaction: beyond the "gold standard”. Clin J Pain 2010;26(8):667-676.

[34] Sikka K, Ahmed AA, Diaz D, Goodwin MS, Craig KD, Bartlett MS, Huang J. Automated assessment of children's post-operative pain using computer vision. Pediatrics 2015. 136(1), e124-e131. DOI: 10.1542/peds.2015-0029

[35] Stanford EA, Chambers CT, Craig KD. A normative analysis of the development of painrelated vocabulary in children. Pain 2005;114:278-284.

[36] Strong CA. The psychology of pain. Psychol Rev 1895;2:329-347.

[37] Sullivan MD, Ballantyne J. Must we reduce pain intensity to treat chronic pain? Pain (in press).

[38] Sullivan MJL. Toward a biopsychomotor conceptualization of pain: implications for research and intervention. Clin J Pain 2008;24(4):281-290.

[39] Walters ET. Injury-related behavior and neuronal plasticity: an evolutionary perspective on sensitization, hyperalgesia and analgesia. Int Rev Neurobiol 1994;36:325-426.

[40] Whitaker AL, Howarth GS. Use of spontaneous behaviour measures to assess pain in laboratory rats and mice: how are we progressing? Appl Animal Behav Sci 2014;151:1-12.

[41] Williams ACdeC. Facial expression of pain: an evolutionary account. Behav Brain Sci 2002;25:439-488.

[42] Williams ACdeC. What can evolution tell us about chronic pain? Pain (in press). 
[43] Williams ACdeC, Eccleston C, Morley S. Psychological therapies for the management of chronic pain (excluding headache) in adults. Cochrane Database of Systematic Reviews 2012, issue 11. Art. No.: CD007409. doi: 10.1002/14651858.cd007407.pub3

[44] Woo CW, Roy M, Buhle JT, Wager TD. Distinct brain systems mediate the effects of nociceptive input and self-regulation on pain. PLOS Biology 2015;13(1): e1002036. doi:10.1371/journal.pbio.1002036

[45] Woo CW, Wager TD. What reliability can and cannot tell us about pain report and pain neuroimaging. Pain (in press).

[46] Zajonc RB. On the primacy of affect. Amer Psychologist 1984;39(2):117-123. 